12

\title{
Особенности накопления энергии \\ в двойном слое на поверхности графенового материала
}

(C) М.Е. Компан ${ }^{1}$, В.Г. Малышкин ${ }^{1, \uparrow, ~ В . П . ~ К у з н е ц о в ~}{ }^{2}$,

В.А. Кривченко ${ }^{3}$

${ }^{1}$ Физико-технический институт им. А.Ф. Иофрфе РАН, Санкт-Петербург

${ }^{2}$ НИИ ГИРИКОНД, Санкт-Петербург

${ }^{3}$ Московский государственный университет им. М.В. Ломоносова

『E-mail: mal@gromco.com

Поступило в Редакцию 17 июля 2016 г.

Рассмотрено влияние особенностей зонной структуры графенов на накопление энергии в суперконденсаторах. Предсказан механизм увеличения плотности накапливаемой энергии на подобных материалах по сравнению с объемными материалами.

DOI: $10.21883 /$ PJTF.2017.03.44231.16433

Широко распространенным техническим решением в области энергонакопления является накопление энергии (и заряда) в двойном электрическом слое [1]. Устройства, реализующие энергонакопление в двойном заряженном слое (англ. EDLC), известны как суперконденсаторы. Электрическая емкость суперконденсаторов пропорциональна площади электродов, поэтому для создания электродов разработчики стремятся использовать графен или материалы на его основе (graphenbased materials, GBM), например в работах [2-4].

Между тем, наряду с максимальной удельной поверхностью, графен как квантовый объект обладает и другими особенностями, влияние которых сказывается и на характеристиках технических материалов, близких к графену. Необходимо также учитывать, что технические графеноподобные материалы могут существенно отличаться как от идеальных графенов, так и между собой. Эти отличия могут быть одной из причин того, что емкостные характеристики электродного материала суперконденсаторов не достигают ожидаемых значений, например $[5,6]$. 
Выяснение особенностей энергонакопления в двойном слое на поверхности графеноподобных материалов и является предметом этой работы.

В работе [7] авторами были рассмотрены емкостные характеристики электродов суперконденсаторов из материалов на основе графенов. В работе еще раз показано, что удельная емкость такого материала эффективно представляет собой последовательное соединение геометрической емкости поверхности в ее традиционном понимании и так называемой квантовой емкости, связанной с плотностью состояний на уровне Ферми. Было показано, что эффективная удельная емкость суперконденсатора с электродами из GBM является функцией накопленного заряда и при определенных условиях может быть существенно, более чем на порядок, меньше той, которую можно было бы ожидать по классическим представлениям.

Следствием уменьшения удельной емкости должно было стать уменьшение энергии, которую можно накапливать на подобных конденсаторах. Подстановка выражения для емкости из [7] в известное выражение для энергии $(E)$ заряженного конденсатора приводит к формуле

$$
E=C_{d l} C_{q w}\left(U_{\max }\right)^{2} / 2\left(C_{d l}+C_{q w}\right),
$$

из которой следует, что предельная плотность накопления энергии должна уменьшиться $\left(C_{d l}, C_{q w}-\right.$ емкость двойного слоя и квантовая емкость соответственно; $U_{\max }$ - максимальное напряжение, до которого можно заряжать конденсатор).

Однако анализ показывает, что существуют механизмы, компенсирующие уменьшение накапливаемой энергии вследствие упомянутого выше уменьшения емкости. Необходимо учесть, что при приложении внешнего напряжения к поверхности GBM это напряжение должно перераспределиться между двойным заряженным слоем у поверхности электрода и квантовой емкостью (как и для всякого последовательного соединения емкостей). Результаты расчета такого перераспределения представлены на рис. 1. На рисунке по горизонтальной оси отложена величина внешнего напряжения, приложенного к электроду из GBM. Часть напряжения, которая при этом будет приходиться на собственно двойной заряженный слой, отложена по правой вертикальной оси. Повышение напряжения на квантовой емкости означает соответствующий подъем энергии Ферми в зоне проводимости (или валентной зоне, в зависимости от знака заряда). Эта величина отложена по левой вертикальной оси.

6 Письма в ЖТФ, 2017, том 43, вып. 3 


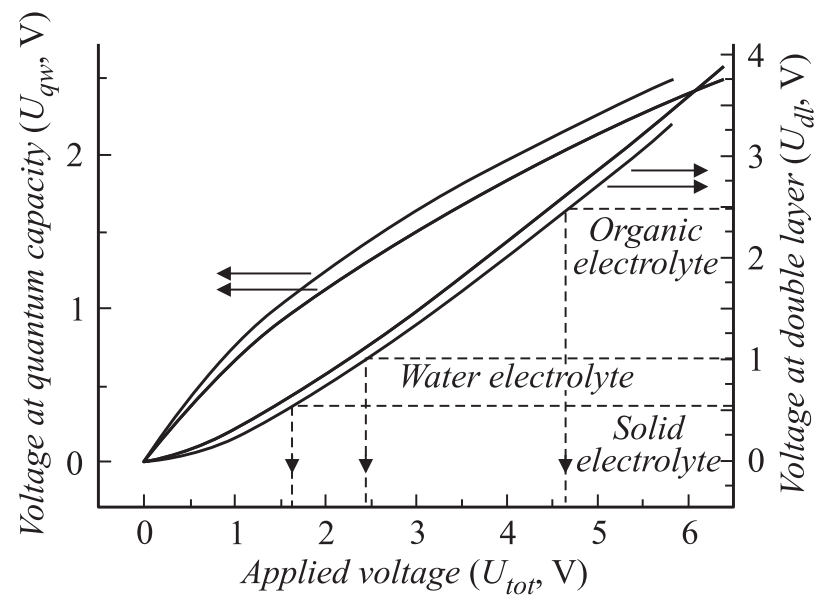

Рис. 1. Зависимость составляющих приложенного напряжения: в двойном заряженном слое у поверхности (по правой оси) и на квантовой емкости (по левой оси) от приложенного внешнего напряжения. Близколежащие пары кривых - для материалов с различным типом легирования.

Две пары кривых (пара для каждого случая) на этом рисунке соответствуют двум типам легирования для GBM. Видно, что для материалов, легированных различным образом, результаты несколько отличаются. Влияние легирования рассмотрено нами в [7].

Поскольку самоочевидной целью всех устройств накопления является накопление возможно большей энергии, суперконденсаторы используют до предельно допустимого для них напряжения. Во всех случаях предельно допустимое напряжение определяется т.н. окном термодинамической стабильности применяемого электролита, т.е. предельным напряжением, при котором не разлагается используемый электролит. Для твердого электролита $\mathrm{RbAg}_{4} \mathrm{I}_{5}$ эта величина составляет около $0.55 \mathrm{~V}$, для электролитов на водной основе около $1 \mathrm{~V}$, для электролитов на базе органических растворителей предельное напряжение в типичном случае составляет $2.5-3 \mathrm{~V}$. С учетом того что на двойном слое остается лишь часть приложенного напряжения, из изложенного выше следует, что суперконденсаторы с электродами на базе GBM можно заряжать заметно большими напряжениями, чем

Письма в ЖТФ, 2017, том 43, вып. 3 
это считалось допустимым. Простейшее геометрическое построение на приведенных графиках (штриховые линии) позволяет установить, какое внешнее напряжение является допустимым для суперконденсаторов в зависимости от типа электролита.

Тот же результат можно получить аналитически. Общее удельное энергонакопление $\left(E_{\text {all }}\right)$ для обсуждаемого случая можно найти как сумму энергий двух последовательных конденсаторов. Для удельных величин можно записать

$$
E_{a l l}=E_{q w}+E_{d l}
$$

Здесь $E_{q w}, E_{d l}$ - энергии, накапливаемые на единице поверхности в квантовой емкости и двойном слое. Еще раз отметим, что формальное „накопление энергии в квантовой емкости“ означает заполнение носителями более высоких уровней в зоне.

С учетом перераспределения напряжений, принимая во внимание, что именно емкость двойного слоя имеет ограничение по предельному напряжению зарядки и что к ней эффективно оказывается присоединен еще один конденсатор, получим выражение для плотности удельной накапливаемой энергии

$$
\begin{aligned}
E_{\Sigma} & =E_{q w}+E_{d l}=C_{d l}\left(U_{\max }\right)^{2} / 2+C_{q w}\left(U_{q w}\right)^{2} / 2 \\
& =C_{d l}\left(U_{\max }\right)^{2} / 2+C_{q w}\left(C_{d l}\right)^{2}\left(U_{\max }\right)^{2} / 2\left(C_{q w}+C_{d l}\right)^{2} .
\end{aligned}
$$

Легко видеть, что первый член полученного выражения точно равен максимально возможной величине накапливаемой энергии, получаемой без учета квантовых эффектов в электроде. Второй член больше нуля, и это означает, что максимально возможная удельная накапливаемая энергия для материалов на базе графенов оказывается выше, чем это получается при классическом рассмотрении. Результат означает, что увеличение предельной накапливаемой энергии может быть получено за счет увеличения напряжения зарядки суперконденсаторов без разложения электролита.

Косвенное подтверждение выдвинутым положениям авторы видят в результатах своих экспериментов по использованию специфического углеродного материала, т.н. „наностенок“ (nanowalls $[8,9]$ ) в качестве активной среды твердотельных суперконденсаторов, конкретно - в особенности вида зарядной кривой и в величине напряжения насыщения.

$6^{*}$ Письма в ЖТФ, 2017, том 43, вып. 3 


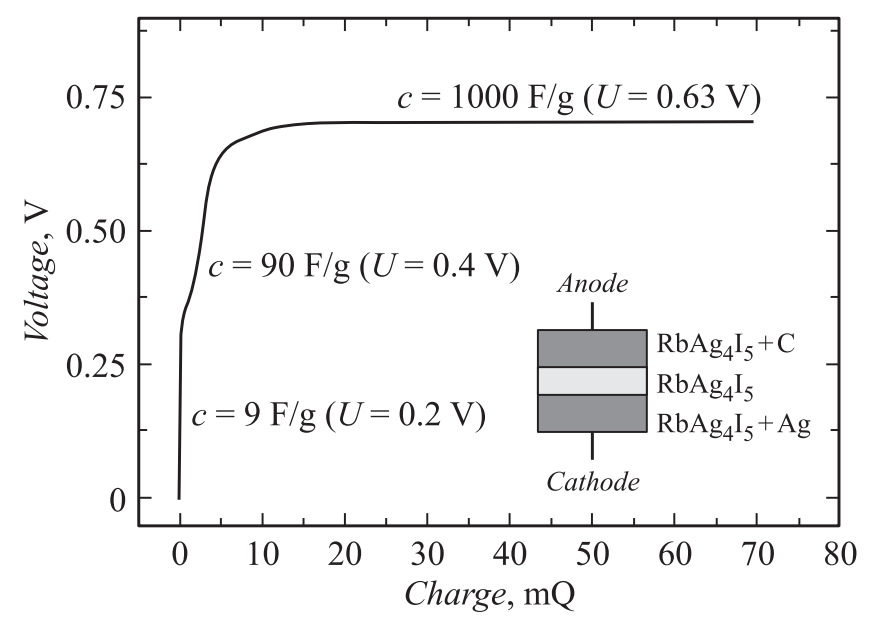

Рис. 2. Зависимость напряжения на твердотельном суперконденсаторе $\left(\mathrm{C}-\mathrm{RbAg}_{4} \mathrm{I}_{5}\right)$ от накопленного заряда. Режим зарядки постоянным током.

В типичном случае пороговое напряжение для границы $\mathrm{RbAg}_{4} \mathrm{I}_{5} /$ углерод составляет $\sim 0.55 \mathrm{~V}$ [10]. При напряжениях порядка $0.1-(0.5-0.55) \mathrm{V}$ зависимость напряжения от величины накопленного заряда линейная, а при увеличении напряжений выше $0.5-0.55 \mathrm{~V}$ зависимость выходит на насыщение, что соответствует разложению электролита и накоплению заряда в фарадеевском (аккумуляторном) режиме.

В экспериментах с „наностенками“ вольт-кулоновские зависимости носили принципиально иной характер. Не считая начальных нелинейностей вблизи нулевых напряжений, зарядные кривые демонстрировали две явно различимые ступени (области перехода к насыщению), а главное - напряжение, достигаемое на второй ступени насыщения, составило $\sim 0.69-0.7 \mathrm{~V}$ (рис. 2 ), что существенно превышает пороговое, установленное многими авторами.

В качестве возможного объяснения наблюдаемой аномалии авторы рассматривают следующую модель. Использованный для анода самоформирующийся углеродный материал — „наностенки“ — предположительно состоит из структурных элементов двух масштабов: относительно крупных, размером в десятки нанометров (что следует из данных по

Письма в ЖТФ, 2017, том 43, вып. 3 


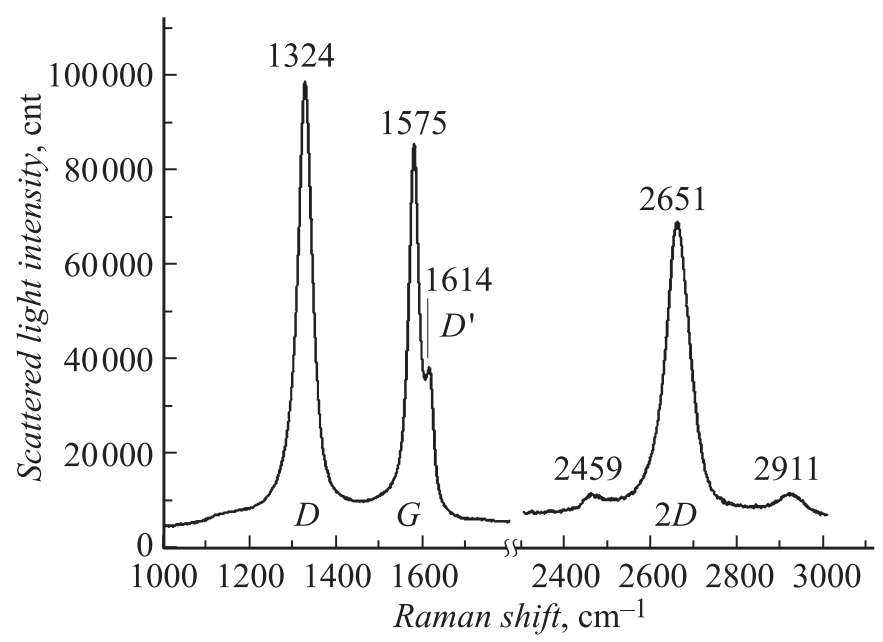

Pис. 3. Спектр рамановского рассеяния света углеродным материалом „наностенки".

трансмиссионной микроскопии [9]) и достаточно хорошо выраженных графеновых фрагментов, которые на фоне массивных „стенок“ не выявляются электронной микроскопией. Аргументы в пользу такого предположения о структуре будут представлены далее.

Исходя из предложенной модели структуры, результаты гальваностатического эксперимента можно интерпретировать следующим образом. Вначале при относительно низких напряжениях достигается пороговое напряжение разложения на массивных фрагментах углеродного материала. Однако для части поверхности, покрытой графеновыми фрагментами, декомпозиция возникает при существенно больших напряжениях $-0.69-0.7 \mathrm{~V}$, что не наблюдалось ранее в экспериментах с другими углеродными материалами и рассматривается нами как возможное подтверждение своих выводов о возможности повышения зарядного напряжения для суперконденсаторов с GBM.

Аргумент в пользу предположения о наличии в структуре материала фрагментов графенов авторы видят в результатах своих экспериментов по неупругому рассеянию света. Рамановский спектр данного материала представлен на рис. 3. В спектре ясно различимы хорошо известные линии, характерные для различных аллотропий углерода: ли-

Письма в ЖТФ, 2017, том 43, вып. 3 
ния $D\left(1330 \mathrm{~cm}^{-1}\right)$, характеризующая наличие $s p^{3}$-углерода, и линия $G$ $\left(1578 \mathrm{~cm}^{-1}\right)$, отвечающая $s p^{2}$-углероду, преобладающая в спектрах графита. В известном случае аморфного углерода спектр содержит обе эти линии, очень широкие и сильно перекрывающиеся. В нашем случае также наблюдается слабый спутник, т.н. линия $D^{\prime}\left(1620 \mathrm{~cm}^{-1}\right)$. Это свидетельствует, что в материале есть хорошо сформировавшиеся области и с $s p^{2}-$, и с $s p^{3}$-конфигурацией.

Интерес представляет линия $2657 \mathrm{~cm}^{-1}$, которую принято обозначать как $2 D$. Эта линия преобладает в спектрах образцов качественных графенов [11]. В спектрах массивных углеродных материалов и даже у „многослойных графенов“ она выражена очень слабо или вообще отсутствует. Таким образом, наличие узкой и интенсивной линии $2 D$ в спектре неупругого рассеяния свидетельствует о возможном наличии в исследуемых „наностенках“ хорошо сформированных графеноподобных фрагментов.

Таким образом, наблюдение двухступенчатой зарядной кривой с насыщением около $0.7 \mathrm{~V}$ (рис. 2) может служить подтверждением высказанного положения, что напряжение разложения электролита на поверхности квантово-размерных углеродных наноструктур может быть выше, чем та же величина для поверхностей массивных углеродных материалов.

В целом в работе рассмотрены особенности накопления энергии в двойном электрическом заряженном слое на поверхности графеноподобного углеродного материала. Показано, что помимо максимальной удельной поверхности графеноподобные материалы в суперконденсатоpax реализуют специфический механизм увеличения удельной накапливаемой энергии, основанный на особенности плотности состояния носителей заряда.

Работа поддержана средствами программы Отделения физических наук РАН.

\section{Список литературы}

[1] Huggins R.A. Energy storage. Springer-Science+Business Media. LLC, 2010. 390 p. DOI 10.1007/978-1-4419-1024-0_1.

[2] Wang Y., Shi Z., Huang Y. et al. // J. Phys. Chem. C. 2009. V. 113. N 30. P. 13103-13107. 
[3] Vivekchand S.R.C., Rout C.S., Subrahmanyam K.S. et al. // J. Chem. Sci. 2008. V. 120. N 1. P. 9-13.

[4] Кузнецов В.П., Компан М.Е., Кравчик А.Е. // Альтернативная энергетика и экология. 2007. Т. 2. В. 7. С. 106.

[5] Campbell P.G., Merrill M.D., Wood M.D. et al. // J. Mater. Chem. A. 2014. V. 2. P. $17764-17770$.

[6] www.skeletontech.com

[7] Компан М.Е., Малышкин В.Г. // Письма в ЖТФ. 2015. Т. 41. В. 8. С. 1-8.

[8] Kobayashi K., Tanimura M., Nakai H. et al. // J. Appl. Phys. 2007. V. 101. P. 094306.

[9] Воронин В.П., Кривченко В.А., Иткис Д.М. и др. // Письма в ЖТФ. 2012. T. 38. В. 17. С. $45-52$.

[10] Иванов-Шии, А.К., Мурин И.В. Ионика твердого тела: В 2 т. СПб.: Изд-во С.-Петерб. ун-та, 2010. 1000 с.

[11] Thomsen C., Reich S. // Phys. Rev. Lett. 2000. V. 85. N 24. P. 5213-5217.

Письма в ЖТФ, 2017, том 43, вып. 3 